\title{
Impactos ambientais da mobilidade urbana: cinco categorias de medidas mitigadoras'
}

\author{
Environmental impacts of urban mobility: \\ five categories of mitigating measures
}

Rafael Barczak ${ }^{[0]}$, Fábio Duarte ${ }^{[b]}$

[a] Arquiteto e urbanista, Mestre em Gestão Urbana pela PUCPR, foi chefe da Divisão de Transportes em São José dos Pinhais, PR - Brasil, e-mail: rafaelbarczak@hotmail.com

[b] Urbanista, Doutor em Comunicações, professor do Programa de Pós-Graduação em Gestão Urbana da Pontifícia Universidade Católica do Paraná (PUCPR/CCET), Curitiba, PR - Brasil, e-mail: duarte.fabio@pucpr.br

\section{Resumo}

Desde 1970 , a emissão de $\mathrm{CO}_{2}$ no setor industrial cresceu $65 \%$ em todo o mundo, contra $120 \%$ no de transportes - e $80 \%$ da energia utilizada para a mobilidade área urbana têm origem na queima de combustíveis fósseis. Assim, a motorização da mobilidade urbana é um dos principais emissores de gases de efeito estufa. Para analisar este cenário, este artigo toma como base a produção científica internacional produzida do Protocolo de Kyoto (1997) à conferência de Copenhague (2008) para levantar quais principais medidas para a redução do impacto ambiental, especialmente das emissões de $\mathrm{CO}_{2}$. Argumenta-se aqui que são cinco os grupos de medidas a partir da discussão de textos técnicos de órgãos internacionais e produção científica, sendo: econômico-fiscais e financeiras; regulatórias; informação e comunicação; planejamento urbano; e tecnológicas.

Palavras-chave: Mobilidade urbana. Impactos ambientais. Medidas mitigadoras.

\begin{abstract}
Since 1970, in a world level emission of $\mathrm{CO}_{2}$ in industry has increased 65 percent; during the same period, it increased up to 120 percent in the transportation sector. And 80 percent of the energy used in urban mobility comes from fossil fuels. The motorization of urban mobility has therefore become one of the main sources of greenhouse gases. We propose here an analysis of this scenario based on papers published by international scientific journals between 1997 (Kyoto Protocol) and 2008 (Copenhage Conference), trying to map which

\footnotetext{
${ }^{1}$ Os autores gostariam de expressar sua gratidão ao CNPq e à Fundação Araucária, pelo apoio à pesquisa que deu origem às discussões presentes neste artigo.
} 
are the main mitigating actions which have been advanced by the scientific community and technical reports by international agencies. We argue here that these actions could be grouped in five categories: financial and economical; regulatory; information and communication; urban planning; and technological.

Keywords: Urban mobility. Environmental impacts. Mitigating measures.

\section{Introdução}

Os padrões atuais de mobilidade urbana, marcada por uma crescente motorização individual, têm elevados custos sociais, econômicos e ambientais. Apesar disso, ações que priorizam a redução de emissões de gases de efeito estufa (GEE) na mobilidade urbana não fazem parte da política efetiva na maioria dos países - mesmo que cada vez mais presentes nos discursos políticos de países desenvolvidos.

$\mathrm{Na}$ comunidade científica parece haver um consenso de que a redução dos deslocamentos motorizados e o estabelecimento de mudanças a favor de modais ambientalmente corretos, a destacar o transporte público e os não motorizados (TNM), constituiriam as estratégias fundamentais para a redução no consumo energético e na mitigação das emissões de GEE.

Fischer et al. (2007) e Halsnaes et al. (2007) colocam que a introdução de combustíveis e tecnologias limpas e os melhoramentos na eficiência energética poderiam ser considerados medidas estruturais, ou building blocks, pois lançam as bases para uma alteração nos processos de produção e consumo final de energia, apresentando grande potencial de redução nas emissões de $\mathrm{CO}_{2}$ nos transportes.

No entanto, Litman (2008c) ressalta que a maioria das estratégias de mitigação das emissões relacionadas à mobilidade urbana concentra-se em medidas tecnológicas. E não é de se estranhar o aumento de investimentos de empresas automotivas com presença global no desenvolvimento de motores mais eficientes que utilizam energia "limpa": trata-se de alternativas para manter o mercado crescente da motorização individual, em especial em países em desenvolvimento, antevendo possíveis restrições que serão impostas pelos países desenvolvidos.

0 mesmo pode ser visto quanto se trata de planejamento urbano, cujo modelo de espalhamento urbano (urban sprawl), que formou a paisagem automobilística dos Estados Unidos, tornou-se corrente em todo mundo. E mesmo se menos poluentes os veículos, esta forma urbana aumenta as distâncias e o número de deslocamentos diários, principalmente em transporte motorizado individual, uma vez que a sua característica baixa densidade não torna economicamente viável o transporte público.

Desse modo, como apontam diversos autores, apenas a combinação de alternativas que vão do melhoramento tecnológico dos motores ao planejamento urbano e de transportes seria eficaz para ao mesmo tempo reduzir o impacto ambiental da motorização e aumentar a qualidade e eficiência dos transportes urbanos.

Quando esse conjunto de medidas é submetido a uma análise custo-efetividade, Wright e Fulton (2005) argumentam que aquelas relacionadas a mudanças no planejamento urbano e de transportes têm custos de redução, expressos em dólares americanos, na ordem de US\$ 14 a US\$ 66 por tonelada de $\mathrm{CO}_{2}$, ao passo que as baseadas sobretudo em combustíveis alternativos possuem custos de redução da ordem de US\$ 148 a US\$ 3.500 por tonelada de $\mathrm{CO}_{2}$.

Ao percorrer a literatura atual sobre as medidas ligadas a transportes que visam à redução dos impactos ambientais da mobilidade urbana, em especial a emissão de GEE, foi possível agrupá-las em cinco categorias. Esses grupos são também fruto do levantamento e da análise inconclusos de artigos científicos publicados de 1997 (Protocolo de Kyoto) a 2009 (Cúpula de Copenhague) em periódicos internacionais constantes na base ISI Web of Science.

Esses cinco grupos de medidas para a redução do impacto ambiental, especialmente na redução das emissões de GEE, são: medidas econômico-fiscais e financeiras; regulatórias; informação e comunicação; planejamento urbano e de transportes; e tecnológicas. 


\section{Medidas mitigadoras: cinco categorias}

\section{Medidas econômico-fiscais e financeiras}

Um dos meios mais eficazes de promover uma mudança no comportamento da sociedade em relação à preservação do meio ambiente é o estabelecimento de instrumentos econômico-fiscais. Mediante a cobrança de tarifas, taxas ou emissão de certificados de poluição pode-se internalizar os custos de atividades degradantes, como também gerar receitas para os órgãos reguladores (LANFREDI, 2007; LUSTOSA; CANEPA; YOUNG; 2003).

A escolha da população por um determinado modo de deslocamento, dentre os disponíveis em uma localidade, tem forte relação com o custo financeiro envolvido - talvez até mais do que outros fatores, como tempo de deslocamento ou conforto. Ou seja, a escolha de um modal é uma decisão de orçamento, que envolve o valor do veículo ou da passagem de transporte público, tarifas de circulação ou preços de estacionamento. Assim, considerando-se que os deslocamentos motorizados individuais vêm se tornando relativamente baratos nos últimos anos, é de se esperar que esta seja a opção crescente nas cidades. Mas por gerarem altos custos externos ao meio ambiente e à sociedade, Breithaupt (2006) salienta que a melhor maneira de inibir seu crescimento é fazer com que os usuários do transporte individual paguem pelo total de custos externos que seus deslocamentos geram.

As principais medidas econômico-fiscais e financeiras aplicadas à mobilidade urbana seguem por duas vertentes: as que penalizam o usuário do transporte motorizado individual, e as que incentivam o usuário do transporte não motorizado ou transporte público. Entre as medidas que penalizam o transporte motorizado individual estão os impostos ou taxas sobre combustíveis, as taxas de registro e licenciamento de veículos, os impostos sobre a circulação de veículos, a taxação para circulação viária (como pedágio urbano), e as taxas de congestionamento e sobre estacionamentos públicos. Entre as medidas que incentivam o uso de transporte público estão os subsídios ou incentivos financeiros à infraestrutura e serviços, ou medidas como os certificados de emissão (BREITHAUPT, 2006; DALKMANN; BRANNIGAN, 2007; LITMAN, 2008a, b; RIBEIRO et al., 2007; SCHWAAB; THIELMANN, 2001;
VICTORIA TRANSPORT POLICY INSTITUTE, 2009; WORLD BUSINESS COUNCIL FOR SUSTAINABLE DEVELOPMENT - WBCSD, 2002, 2004).

Tomando como exemplo uma medida que já é adotada em diversas cidades do mundo, e sempre volta à pauta quanto se trata de grandes centros urbanos no Brasil, tem-se a cobrança de taxas para a circulação de veículos motorizados em determinados setores da cidade - com isso, potencialmente reduzindo o número de veículos que circulariam por esta região. 0 caso mais conhecido provavelmente seja o de Londres, que cobra pedágio urbano para a circulação em determinadas áreas da cidade.

Essa é uma das medidas que de fato podem contribuir para a redução das emissões de GEE na mobilidade, pois além de reduzir os congestionamentos e incrementar a velocidade do tráfego, podem estimular o uso de meios alternativos de transporte (DALKMANN; BRANNIGAN, 2007). Todavia, em determinadas situações ela pode penalizar alguns grupos sociais, ao restringir o acesso a serviços urbanos. Como colocam Dalkmann e Brannigan (2007, p. 26), "na medida em que se introduz ou aumenta a taxação nos centros urbanos, corre-se o risco de estimular uma dispersão urbana". Ou seja, inibidos de usar determinadas áreas centrais da cidade, com circulação ora taxada, os usuários usariam outras regiões, havendo, assim, apenas uma transferência do tráfego de uma região para outra. Isso poderia acarretar o aumento das distâncias de deslocamento e, consequentemente, do consumo de combustíveis.

Impostos sobre os combustíveis elevam o seu preço final, podendo resultar tanto na redução dos deslocamentos motorizados individuais (o que seria benéfico), como em um estímulo à substituição dos veículos em circulação por veículos energeticamente mais eficientes. Isto, se em uma primeira tomada, seria também benéfico pela redução da emissão dos GEE, não alteraria os padrões de deslocamentos, mantendo e agravando as outras externalidades negativas do transporte individual motorizado em larga escala - como os congestionamentos veiculares e as deseconomias a eles atreladas (VASCONCELLOS, 1998).

Uma resposta alternativa às taxas sobre combustíveis para a redução das emissões de GEE estaria na aplicação de impostos sobre o registro e a circulação de veículos. Mesmo com taxas diferenciais pela eficiência energética e redução de emissões 
dos veículos, ela incidiria em todos os veículos motorizados individuais, como meio de desestimular o seu uso.

Em uma visão ao mesmo tempo oposta e complementar, Litman (2008a) ressalta que os impostos veiculares são taxas fixas e não fundamentadas na quantidade de deslocamentos realizados. Como os custos externos que os deslocamentos em automóveis geram, notadamente em acidentes e poluição, aumentam na medida em que aumentam as viagens, para o autor, essas taxas deveriam incidir sobre os veículos em função da quantidade deslocada (pay-as-you-drive pricing). Tal taxação criaria oportunidades para que os motoristas pudessem economizar financeiramente e, ao mesmo tempo, incentivos para uma redução dos deslocamentos motorizados, minimizando problemas relacionados ao tráfego, ao consumo energético e às emissões.

Para Litman (2008a, b), seriam as Win-Win Transportation Solutions. O autor ainda ressalta que as estratégias win-win podem reduzir entre $30 \%$ e $50 \%$ os custos gerados pelos deslocamentos motorizados.

O Quadro 1 exemplifica casos internacionais de aplicação de algumas das medidas anteriormente discutidas, salientando os objetivos e resultados potenciais em termos de redução no consumo energético e nas emissões de $\mathrm{CO}_{2}$. Neste quadro estão apresentados os nomes de cidades ou países que já adotaram cada uma das medidas, o nome delas, os objetivos e resultados esperados, e algumas das referências onde elas são discutidas.

\section{Medidas regulatórias}

As medidas regulatórias seguem o enfoque da política de comando e controle, tendo por objetivo fundamental a determinação de especificações, normas e padrões, visando à proibição ou restrição de atividades potencialmente poluidoras (BREITHAUPT, 2006; LUSTOSA; CANEPA; YOUNG, 2003).

Em se tratando de uma política de redução das emissões de $\mathrm{CO}_{2}$ na mobilidade urbana, essas medidas "direcionam tanto ao desestímulo de deslocamentos motorizados como ao impedimento completo de acesso a determinados meios de transporte" (DALKMANN; BRANNIGAN, 2007, p. 18). Entre as principais estão a regulação do consumo de combustíveis, o estabelecimento de padrões e limites de emissão para combustíveis e veículos, medidas de restrição física e de regulação de estacionamentos, de gestão e controle de tráfego e limites de velocidade, e de manutenção e inspeção veicular.

0 estabelecimento de padrões de eficiência (Fuel Efficiency Standards) são medidas de controle sobre combustíveis ou tecnologias veiculares que objetivam a introdução no mercado de tecnologias mais eficientes e com menor nível de emissão de poluentes (LITMAN, 2008b).

Em situações em que o estabelecimento de padrões de emissão para todos os tipos de veículos é difícil de ser implantado, em função dos elevados custos envolvidos, especialmente nos países em desenvolvimento, Kolke (2006) salienta que um programa de inspeção e manutenção veicular pode ser uma alternativa para melhorar a qualidade do ar e a segurança no trânsito. Segundo Vasconcellos (2006, p. 179), "a inspeção veicular é uma das medidas mais importantes para assegurar que os veículos estejam emitindo uma quantidade aceitável de poluentes".

Medidas de restrição física variam em termos de horários, duração e severidade na regulação, desde proibições temporárias ao tráfego motorizado, a exemplo das operações de rodízio de veículos, ao impedimento definitivo de acesso às áreas centrais por automóveis (Car-free Zones) (DALKMANN; BRANNIGAN, 2007; WBCSD, 2002). No caso dos rodízios, um efeito colateral que se observou em algumas cidades, como em São Paulo e Bogotá, foi a compra de um segundo veículo, com emplacamento diferente que permita que um deles sempre possa circular.

Não há estudos conclusivos sobre o tema, mas principalmente opinativos (SCARINGELLA, 2001); esse é um argumento que o próprio Detran (Departamento Estadual de Trânsito) utiliza para inibir a implantação de rodízios em algumas cidades no Brasil². Além de manter a circulação

\footnotetext{
2 O Detran considerou a eventual compra de um segundo veículo como razão para descartar o rodízio de veículos em Brasília, como noticiado pelo site UOL. Ver ANDRADE, 2008.
} 
Quadro 1 - Exemplos da aplicação de medidas econômico-fiscais e financeiras na Mobilidade

\begin{tabular}{|c|c|c|c|}
\hline Cidade/países & Medidas & Objetivos/Resultados potenciais & Referência \\
\hline \multicolumn{4}{|c|}{ Taxação viária (Road Pricing; Congestion Pricing) } \\
\hline Singapura & $\begin{array}{l}\text { Eletronic Road } \\
\text { Pricing (ERP) }\end{array}$ & $\begin{array}{l}0 \text { sistema ERP foi implantado em } 1998 \text { para substituir o sistema de pedágio urbano existente } \\
\text { desde 1970, o Area Licensing Scheme (ALS). Consiste em um sistema eletrônico utilizado para } \\
\text { controlar o fluxo de tráfego e congestionamentos na zona central, com uma diferenciação de } \\
\text { tarifas de acordo com os dias e horários e de acordo com o tamanho dos veículos. } 0 \text { tráfego de } \\
\text { veículos privados foi reduzido em } 75 \% \text {, com uma economia de energia de aproximadamente } \\
1.043 \mathrm{GJ} / \text { dia. }\end{array}$ & $\begin{array}{l}\text { BREITHAUPT, } 2000 \\
\text { SCHWABB; THIELMANN, } 2001 \\
\text { WRIGHT, } 2005 \\
\text { RIBEIRO et al., } 2007\end{array}$ \\
\hline $\begin{array}{l}\text { Seoul, Coreia } \\
\text { do Sul }\end{array}$ & Pedágio urbano & $\begin{array}{l}\text { A medida da taxação viária foi introduzida nos túneis } \mathrm{n} \text {. } 1 \text { e n. 3, que conectam o centro à } \\
\text { porção sul da cidade. Estabelecendo uma isenção de pagamento de tarifas para ônibus, vans } \\
\text { e automóveis com mais de três passageiros, tal medida resultou em uma redução de 34\% no } \\
\text { volume de tráfego em horários de pico e aumentou em } 50 \% \text { a velocidade média. }\end{array}$ & $\begin{array}{l}\text { DALKMANN; BRANNIGAN, } 2007 \\
\text { RIBEIRO et al., } 2007\end{array}$ \\
\hline Londres, Inglattera & Pedágio urbano & $\begin{array}{l}\text { A medida entrou em operação em 2003, cobrindo a zona central de Londres, estendida em } 2007 . \\
\text { Para acessar essa área, os motoristas precisam pagar taxas de aproximadamente US\$ } 16 \text {. A } \\
\text { medida foi tomada em coniunção com uma melhoria no sistema de transporte público. Como } \\
\text { resultado, o tráfego de veículos na área central caiu 40\%, houve um incremento de } 20 \% \text { na } \\
\text { velocidade dos ônibus e redução de 20\% nas emissões de C } \mathrm{CO}_{2} \text {. }\end{array}$ & $\begin{array}{l}\text { WRIGHT, } 2005 \\
\text { VASCONCELLOS, } 2006 \\
\text { DALKMANN; BRANNIGAN, } 2007 \\
\text { RIBEIRO et al., } 2007\end{array}$ \\
\hline \multicolumn{4}{|c|}{ Taxação de estacionamentos (Parking Pricing; Park \& Ride) } \\
\hline $\begin{array}{l}\text { San Sebastian, } \\
\text { Espanha }\end{array}$ & Park \& Ride & $\begin{array}{l}\text { A aplicação de elevadas tarifas para estacionamento em áreas centrais e a ausência de cobrança } \\
\text { nos estacionamentos implantados em estaçōes de transporte público criam incentivos para uma } \\
\text { redução do transporte motorizado e uma mudança a favor do transporte público. }\end{array}$ & SCHWAAB; THIELMANN, 2001 \\
\hline $\begin{array}{l}\text { Bremen, } \\
\text { Alemanha }\end{array}$ & Parking Pricing & $\begin{array}{l}\text { Essa medida tem por objetivo estabelecer uma regulaccão sobre todas as áreas de estacionamento } \\
\text { nas regiões centrais, impondo tarifas elevadas em determinados setores e fazendo com que } 0 \\
\text { custo para utilizar e estacionar os automóveis seja maior que o custo de utilização do transporte } \\
\text { público. Como resultado, o transporte público contabiliza } 50 \% \text { dos deslocamentos realizados } \\
\text { nas áreas centrais, ao passo que o TNM, 22\%. }\end{array}$ & $\begin{array}{l}\text { SCHWAAB; THIELMANN, } 2001 \\
\text { BREITHAUPT, } 2006\end{array}$ \\
\hline \multicolumn{4}{|c|}{ Impostos sobre veículos (Vehicle Tax; Pas-As-You-Drive Pricing) } \\
\hline Alemanha & $\begin{array}{l}\text { Imposto sobre } \\
\text { a propriedade } \\
\text { veicular }\end{array}$ & $\begin{array}{l}0 \text { imposto anual sobre a propriedade de automóveis e caminhões é aplicado em relação à } \\
\text { potência do motor do veículo, de modo a fixar tarifas tanto em relação ao tipo de combustível } \\
\text { como ao nível de emissões. } 0 \text { objetivo é incentivar o câmbio para o uso de veículos menos } \\
\text { poluentes. }\end{array}$ & $\begin{array}{l}\text { SCHWAAB; THIELMANN, } 2001 \\
\text { BREITHAUPT, } 2006\end{array}$ \\
\hline \multicolumn{4}{|c|}{ Imposto sobre combustíveis (Fuel Tax; Carbon Tax) } \\
\hline Alemanha & Ecotaxas & $\begin{array}{l}\text { A aplicação dessas taxas sobre os combustíveis derivados do petróleo tem por objetivo aumentar } \\
\text { os preços dos combustiveis de modo a criar incentivos para maior eficiência energética e criar } \\
\text { receitas para o financiamento de infraestrutura de transporte público. Como resultado, num } \\
\text { primeiro momento, essa medida auxiliou na mudança de padrões de condução veicular e em } \\
\text { longo prazo e contribui para a introdução de veículos menos intensos em consumo energético } \\
\text { e emissões. }\end{array}$ & SCHWAAB; THIELMANN, 2001 \\
\hline \multicolumn{4}{|c|}{ Subsídios, incentivos e compensações financeiras (Parking Cash Out; MDL; GEF) } \\
\hline $\begin{array}{l}\text { Bogotá, } \\
\text { Colômbia }\end{array}$ & $\begin{array}{l}\text { MDL em projeto } \\
\text { BRT }\end{array}$ & $\begin{array}{l}\text { Atualmente, é o melhor projeto de transporte registrado como Mecanismo de Desenvolvimento } \\
\text { Limpo. } 0 \text { projeto Transmilenio, como é conhecido, foi projetado e está sendo implementado } \\
\text { como um sistema BRT, com } 130 \mathrm{~km} \text { de linhas exclusivas para ônibus de alta capacidade até } \\
0 \text { ano de } 2012 \text {, quando seŕá iniciada a contabilizacãão das reduçōes de } \mathrm{CO}_{2} \text { por um período } \\
\text { inicial de sete anos. A medida tem por objetivo a reduccão de aproximadamente } 7 \text { milhões de } \\
\text { toneladas de } \mathrm{CO}_{2} \text { para os próximos } 30 \text { anos, a um custo de US } \$ 20 \text { por tonelada. }\end{array}$ & $\begin{array}{l}\text { GRUTTER, } 2007 \\
\text { WALKER; KING, } 2008\end{array}$ \\
\hline
\end{tabular}


constante, o segundo veículo traz ainda outros dois problemas: o primeiro é que normalmente o segundo veículo é mais simples, sem a eficiência energética e de emissões do primeiro; e o segundo é que, havendo a disponibilidade de outro veículo em casa, nos dias em que os dois carros estiverem liberados para circulação, isto se torna um incentivo para que outros usuários, outrora do transporte público, utilizem o carro.

Dalkmann e Brannigan (2007) ainda destacam a implantação de zonas de baixa emissão (Low Emission Zones), que restringem o acesso a certas áreas de veículos que não cumprem um determinado padrão de emissões.

Os carros parados em congestionamentos poluem muito mais do que circulando. Assim, medidas como a coordenação de semáforos compatíveis com o volume do tráfego, regulação de estacionamentos e a implantação de pistas exclusivas para veículos com maior capacidade de transporte de passageiros podem contribuir significativamente para uma redução nas emissões (DALKMANN; BRANNIGAN, 2007; VASCONCELLOS, 2006; VTPI, 2009).

0 Quadro 2 apresenta exemplos de aplicação de algumas medidas regulatórias, salientando os objetivos e resultados potenciais em termos de incremento na qualidade do ar, contribuições para a melhoria das condições de mobilidade e possíveis efeitos diretos e indiretos na redução das emissões de $\mathrm{CO}_{2}$.

\section{Medidas de informação e comunicação}

A definição da importância das medidas de informação e comunicação poderia partir de uma consideração da Associação Nacional de Transportes Públicos (ANTP):

Contribuir com ações que serão compartilhadas com a população, para mantê-la informada e gerar um processo de conscientização que levará a uma mudança gradual de comportamento e à co-participação democrática da sociedade na discussão dos problemas de trânsito (ANTP, 2003, p. 106).

Medidas de comunicação, informação e educação atuam, portanto, diretamente na mudança de hábitos e comportamento das pessoas, auxiliando na efetividade de outras medidas, mais rigorosas, que objetivam a mitigação de problemas relacionados aos atuais padrões de mobilidade - neste caso, as emissões de $\mathrm{CO}_{2}$.

Campanhas educativas e de sensibilização são medidas especialmente importantes para cidades de países em desenvolvimento, pelo baixo custo de implementação, alto impacto na divulgação dos assuntos relacionados ao transporte sustentável e, pela possibilidade de formação de alianças entre a população e os atores engajados na formulação das políticas públicas (PARDO, 2006).

Em se tratando de uma estratégia que visa à redução das emissões na mobilidade, Pardo (2006) ressalta que, para que tenham um efeito positivo, essas campanhas devem promover atividades múltiplas que estimulem as pessoas a utilizar meios alternativos de transporte, principalmente o transporte público e TNM.

Um dos exemplos mais citados para a promoção destes modais é fomentar eventos "Dias sem carro", restringindo o uso de veículos motorizados individuais nas cidades, ou em setores, por um dia ou durante um horário pré-definido para demonstrar a viabilidade das alternativas de transporte em um dia de trabalho típico (WRIGHT, 2006). Em Bogotá, no mesmo período em que o seu transporte público de massa estava sendo implantado, chamado Transmilenio, a cidade criou o dia sem carro, que hoje cobre dezenas de ruas em diversos bairros da cidade nos domingos. Além de criar áreas públicas de convívio, importante principalmente nas regiões desprovidas de parques e praças, há o incentivo ao deslocamento não motorizado.

Contrariamente ao planejamento tradicional, normativo, "cria-se aqui a necessidade da inclusão dos diversos atores para tornar possível a síntese do objeto planejado em sua completude" (BRASIL, 2006, p. 70), considerando as diferentes dimensões e pontos de vista do problema por meio de uma prática comunicativa de planejamento.

Em outras palavras, trata-se aqui de medidas de gerenciamento da mobilidade (mobility management) que, diferente das medidas de gestão das demandas de tráfego, de caráter mais restritivo e regulatório, incentivam a mudança na escolha dos deslocamentos por meio de ferramentas de informação, comunicação, motivação e organização, perfazendo o grupo de medidas com uma maior aceitação pela sociedade (SCHMITT, 2006). 
Quadro 2 - Exemplos da aplicação de medidas regulatórias na mobilidade

\begin{tabular}{|c|c|c|c|}
\hline Cidades/países & Medidas & Objetivos/resultados potenciais & Referência \\
\hline \multicolumn{4}{|c|}{ Padrões de emissão veicular (Fuel Efficiency Standards) } \\
\hline Europa & $\begin{array}{l}\text { European Emission } \\
\text { Standards }\end{array}$ & $\begin{array}{l}\text { Padrões de emissão para novos veículos vendidos na Europa. Aplicados a veículos } \\
\text { leves (EURO I; EURO 2; EURO 3; EURO 4; EURO 5; EURO 6) e veículos pesados } \\
\text { (EURO I; EURO II; EURO III; EURO IV; EURO V), com o objetivo de limitar } \\
\text { gradualmente a quantidade de emissões de poluentes locais (NOx; HC; CO; PM). } \\
\text { Atingir os padrões determinados significa melhorar a eficiência e a qualidade de } \\
\text { combustiveis, a exemplo do Diesel, e as novas tecnologias veiculares. A melhoria } \\
\text { tecnológica envolvida pode contribuir para redução das emissões de GEE. }\end{array}$ & VASCONCELLOS, 2006 \\
\hline \multicolumn{4}{|c|}{ Restrição Física (Rodízio; Car-free Zones; Low Emission Zones; Traffic Calming; Restrições de estacionamentos) } \\
\hline São Paulo, Brasil & Rodízio & $\begin{array}{l}\text { Foi implantado com o objetivo primordial de reduzir os congestionamentos. } \\
\text { A restrição de circulação abrangia } 20 \% \text { dos veículos diariamente, segundo a } \\
\text { numeração da placa e inicialmente levou a uma redução de } 12 \% \text { na quantidade } \\
\text { de veículos em circulação, com uma redução de } 30 \% \text { na lentidão de tráfego. No } \\
\text { entanto, o aumento da frota de veículos, a compra de veículos adicionais e a } \\
\text { carência na fiscalizacãão diminuíram significativamente sua eficiência. }\end{array}$ & VASCONCELLOS, 2006 \\
\hline Bogotá, Colômbia & Pico y Placa & $\begin{array}{l}\text { Programa da administração pública que tem por objetivo incentivar uma mudança } \\
\text { de uso dos automóveis privados para o transporte público. Duas vezes por semana, } \\
\text { os automóveis são proibidos de circular nos horários de pico, de acordo com } 0 \\
\text { final da placa. Essa medida reduziu em } 40 \% \text { o uso de automóveis, diminuindo } \\
\text { significativamente os congestionamentos nas horas pico. Projeta-se para o ano de } \\
2015 \text { a restrição total de veículos em horários de pico. }\end{array}$ & MONTEZUMA, 2003 \\
\hline Copenhagen, Dinamarca & Car-free Zones & $\begin{array}{l}\text { Desde o fechamento da primeira via ao tráfego de veículos em 1962, a } \\
\text { participação popular em atividades sociais e culturais na área central ficou mais } \\
\text { de três vezes maior. Além de promover mais interação social, a pedestrianização } \\
\text { de vias levou a um ganho de } 14 \mathrm{~m}^{2} \text { por habitante, o que reforça uma mudança } \\
\text { no comportamento e nos hábitos da populaçã̃o e resulta na redução de } \\
\text { deslocamentos em automóveis. }\end{array}$ & WRIGHT, 2006a \\
\hline \multicolumn{4}{|c|}{ Gestão de tráfego (Intelligent Transport System - ITS; HOV priority; Ridesharing; Carpooling; Vanpooling) } \\
\hline Singapura & GLIDE (ITS) & $\begin{array}{l}\text { Aimplantação do sistema GLIDE (Green Light). Trata-se de um sistema inteligente } \\
\text { de sinais, cobrindo } 1.850 \text { intersecç̃oes viárias, que tem por objetivo a gestão do } \\
\text { tráfego veicular por meio da priorização do transporte coletivo. }\end{array}$ & SAYEG; CHARLES, 2005 \\
\hline Brisbane, Austrália & $\begin{array}{l}\text { Coronation Drive Tidal Flow } \\
\text { (ITS) }\end{array}$ & $\begin{array}{l}\text { Trata-se de um sistema inteligente de sinais implantado em um corredor radial de } \\
2,5 \mathrm{~km} \text { de extensão no distrito central da cidade, com um volume de tráfego de } \\
\text { aproximadamente } 6.000 \text { veículos/hora. } 0 \text { sistema consiste em um conjunto de } \\
\text { sinais que podem alterar a direção do fluxo de modo a sempre alocar uma pista } \\
\text { exclusiva para o transporte coletivo. }\end{array}$ & SAYEG; CHARLES, 2005 \\
\hline \multicolumn{4}{|c|}{ Inspeção veicular e manutenção } \\
\hline Santiago, Chile & 3CV & $\begin{array}{l}0 \text { Centro de Controle e Certificação Veicular (3CV) foi implantado na Região } \\
\text { Metropolitana de Santiago do Chile em 1992, com o objetivo de implementar } \\
\text { ações de inspeccão sobre veículos novos. As emissões veiculares foram reduzidas } \\
\text { em até 45\%, dependendo do poluente considerado. }\end{array}$ & $\begin{array}{l}\text { GOEDEKING, } 2004 \\
\text { KOLKE, } 2006\end{array}$ \\
\hline
\end{tabular}

Fonte: BARCZAK, 2009.

Dentre as medidas de gerenciamento da mobilidade, destacam-se as estratégias que dão prioridade ao tráfego de veículos com maior número de ocupantes (High Occupant Vehicle priority), incentivando o uso do transporte coletivo e o uso compartilhado de veículos (Ridesharing; Carpooling; 
Vanpooling), de modo a diminuir a quantidade de veículos em circulação, melhorando as condições de tráfego e tornando o uso das vias mais eficiente (LITMAN, 2008b). Medida similar foi adotada em São Paulo, com a liberação das faixas exclusivas de ônibus para táxis ocupados. Além dessas medidas, as tecnologias de informação e comunicação também se destacam, tanto no gerenciamento da mobilidade urbana quanto na mudança de hábitos dos cidadãos.

Informação em tempo real via Internet, SMS, GPS ou outros meios de comunicação, sobre os serviços de transporte existentes, horários e melhores rotas, inclusive a existência de congestionamentos ou pontos de lentidão no tráfego, podem auxiliar na mudança das estratégias individuais de deslocamentos e tornar o transporte público mais desejável e eficiente (SAYEG; CHARLES, 2005).

É, por exemplo, o que menciona Schmitt (2006) em relação aos sistemas de informação aos usuários de transporte coletivo (SIU), cuja finalidade é fornecer informações relevantes e oportunas sobre os serviços de transporte público diretamente aos usuários, podendo tanto melhorar a eficiência dos serviços como constituir em importante ferramenta para a qualificação do transporte público.

Em estudo aplicado em área urbana específica da cidade de Porto Alegre, uma avaliação da satisfação dos entrevistados em relação ao transporte público evidenciou um grande potencial de mudança do modal automóvel para o modal transporte público, caso fosse implementado um SIU com uma maior disponibilidade de informações (SCHMITT, 2006).

Outro aspecto que vem sendo discutido dentre as medidas de informação e comunicação é a conscientização dos motoristas sobre como o seu comportamento afeta não só a qualidade do trânsito, como também pode contribuir para a redução das emissões de $\mathrm{CO}_{2}$, chegando a $25 \%$, segundo Dalkmann e Brannigan (2007).

A chamada condução ecológica (Ecodriving) é um conjunto de estratégias que compreendem desde a manutenção correta e periódica dos veículos à alteração do comportamento do condutor, principalmente no que se refere à manutenção de velocidades constantes, situações de parada e aceleração desnecessárias e à minimização de viagens curtas (BREITHAUPT; EBERZ, 2005; DALKMANN; BRANNIGAN, 2007).
O Quadro 3 exemplifica alguns casos de melhores práticas na aplicação de instrumentos de comunicação e informação na mobilidade urbana e que podem contribuir para a redução das emissões de $\mathrm{CO}_{2}$ e prover outros benefícios locais.

Essas medidas vão desde movimentos para a reapropriação dos espaços públicos das vias durante os finais de semana, como o fechamento ao tráfego de dezenas de importantes avenidas em Bogotá, na Colômbia, até o levantamento da distribuição modal nas cidades brasileiras, feito pela ANTP, que pode servir como um parâmetro consolidado para eventuais políticas nacionais sobre transportes em grandes centros urbanos.

\section{Medidas de planejamento e desenho urbano}

A ocupação intensiva, e muitas vezes descontrolada, do solo urbano tem aumentado a pressão na demanda por recursos naturais e materiais, exercendo pressão cada vez maior sobre o meio físico natural circundante. Alguns autores colocam que o que se deve buscar é um padrão de desenvolvimento urbano sustentável, que implicaria no "reordenamento ecológico do território, a revisão das formas de assentamento, dos modos de produção e dos padrões de consumo" (LEFF, 2001, p. 287); ou, ainda, na "redistribuição espacial da pressão técnica de populações e atividades sobre a base de recursos ambientais urbanos" (ACSELRAD, 2001, p. 39).

0 "novo urbanismo" (do inglês new urbanism ou neotraditional development) advoga estratégias de desenho urbano fundamentado nas tradicionais vizinhanças anteriores ao urbanismo moderno, com foco no pedestre. Ele é visto por alguns autores como um estágio para a sustentabilidade urbana $\mathrm{e}$ a contribuição para a redução do consumo de energia, aos baixos níveis de poluição e produção de lixo, a redução do uso do automóvel, a preservação dos ecossistemas e a orientação para ambientes de convivência e contato social (JABAREEN, 2006).

Esforços em resgatar formas urbanas mais compactas, que privilegiam o caminhar e o contato entre as pessoas, estão associados com a necessidade de construir o senso de comunidade nas cidades, reforçando a identidade local e o sentido de pertencimento da população como o primeiro passo para se alcançar a sustentabilidade (DAY, 2003; KENWORTHY, 
Quadro 3 - Exemplos de aplicação de medidas de informação e comunicação na mobilidade

\begin{tabular}{|c|c|c|c|}
\hline Cidades/países & Medidas & Objetivos/resultados potenciais & Referência \\
\hline \multicolumn{4}{|c|}{ Campanhas de Sensibilização (Car-free days) } \\
\hline Bogotá, Colômbia & Ciclovia (Car-free days) & $\begin{array}{l}\text { Programa de restrição veicular aos domingos e feriados, quando mais de } 120 \\
\text { km de vias são fechadas ao tráfego de veículos e transformadas em áreas livres } \\
\text { para atividades culturais e para a circulaçãa de ciclistas e pedestres. }\end{array}$ & $\begin{array}{l}\text { MONTEZUMA, } 2003 \\
\text { WRIGHT, 2006a }\end{array}$ \\
\hline Europa, Ásia, América Latina & World Car-free Day & $\begin{array}{l}\text { Instituído em decorrência do Dia da Terra, como um evento de sensibilizaç̃̃o } \\
\text { sobre questões ecológicas, o Dia Mundial sem Carros é um evento internacional } \\
\text { que ocorre anualmente no dia } 22 \text { de setembro, em mais de mil cidades } \\
\text { do mundo, com o objetivo de restringir } 0 \text { uso do automóvel e incentivar a } \\
\text { utilização do transporte público e TNM. }\end{array}$ & WRIGHT, $2006^{\circ}$ \\
\hline \multicolumn{4}{|c|}{ Sistema de Informação (ITS) } \\
\hline Singapura & i-Transport & $\begin{array}{l}\text { Também chamado Integrated Transport Management System (ITMS), trata-se } \\
\text { de um sistema em fase de implementação desde 1997, destinado a integrar } \\
\text { todos os ITS de modo a fornecer informaçōes em tempo real sobre todos os } \\
\text { modos de deslocamento: informaçóes de tráfego (Traffic Smart), informaçōes } \\
\text { sobre os serviços de transporte público (Transit Smart) e a integração dessas } \\
\text { em um sistema multimodal (Route Smart). }\end{array}$ & SAYEG, CHARLES, 2005 \\
\hline Brasil & $\begin{array}{l}\text { Sistema de Informações } \\
\text { de Mobilidade Urbana }\end{array}$ & $\begin{array}{l}\text { Desenvolvido pela Associação Nacional de Transportes Públicos (ANTP) em } \\
\text { parceria com o BNDES, consiste em um banco de dados com acesso livre a } \\
\text { múltiplas informações sobre o estado real da mobilidade urbana dos municípios } \\
\text { brasileiros com populacãão superior a } 60.000 \text { habitantes, nas diversas áreas do } \\
\text { transporte e mobilidade urbana. }\end{array}$ & ANTP, 2008 \\
\hline \multicolumn{4}{|c|}{ Treinamento e educação de condutores (Ecodriving) } \\
\hline Stuttgart, Alemanha & $\begin{array}{l}\text { Computer Based Training } \\
\text { (CBT) }\end{array}$ & $\begin{array}{l}\text { Consiste em um sistema de aprendizagem baseado em métodos multimídia, } \\
\text { desenvolvido para sua aplicação em qualquer região, com o foco na capacitação } \\
\text { de motoristas para uma condução segura, econômica e consciente em relação } \\
\text { ao meio ambiente. Amplamente aplicado a operadores de ônibus na União } \\
\text { Europeia e América Latina, o Bus Driver Training tem resultado em economia de } \\
\text { combustível, por parte dos motoristas de ônibus, que chega a 10\% com uma } \\
\text { redução igual na poluição atmosférica e reduções de até } 30 \% \text { nos acidentes } \\
\text { de trânsito. }\end{array}$ & BREITHAUPT; EBERZ, 2005 \\
\hline \multicolumn{4}{|c|}{ Participação popular (ONGs; Planejamento estratégico) } \\
\hline São Paulo, Brasil & Ciclo Rede & $\begin{array}{l}\text { Iniciativa conjunta entre a administraçãa pública e ONGs pró-bicicleta. Consiste } \\
\text { na criaccão e divulgaccão de um mapa-guia com as melhores rotas para o uso } \\
\text { da bicicleta em uma área de } 40 \mathrm{~km}^{2} \text { : vias com menor volume e velocidade } \\
\text { de tráfego, pequena inclinaçãa e grande número de conexões entre serviços } \\
\text { públicos. O objetivo é incentivar o uso da bicicleta em deslocamentos curtos } \\
\text { (como é a maioria dos realizados diariamente na cidade). }\end{array}$ & PARD0, 2006 \\
\hline Perth, Austrália & Dialogue with The City & $\begin{array}{l}\text { Processo de planejamento estratégico municipal iniciado em 2003, com } \\
\text { a participacção de } 42 \text { áreas da administracção pública, iniciativa privada e } \\
\text { sociedade civil, na construção de uma imagem global da cidade para o ano } \\
\text { de } 2030 \text {, enfatizando a sustentabilidade urbana. Uma das linhas de ação é } \\
\text { o plano The Network City, cujo objetivo é que em torno de } 60 \% \text { das novas } \\
\text { construcõoes ocorram em vazios urbanos, a fim de reduzir a dispersão e a } \\
\text { dependência de automóveis. }\end{array}$ & KENWORTHY, 2006 \\
\hline
\end{tabular}

Fonte: BARCZAK, 2009. 
2006). O problema do novo urbanismo é que as principais cidades que o adotaram estão no nordeste dos Estados Unidos e não possuem o adequado mix de residência, serviços e trabalho. Normalmente próximas a grandes centros urbanos, a vida em seu interior é aparentemente equilibrada; porém, por serem altamente dependentes de grandes centros, mantêm altos índices de motorização individual. Como coloca Newman (2006, p. 277), "os subúrbios de baixa densidade podem ser mais degradantes que áreas de alta densidade, pela extensão de solo perdido e a dependência em automóveis que implicam". Ou seja, se no interior dos assentamentos construídos sob os princípios do novo urbanismo há uma tentativa de criação de ambientes mais amigáveis ao transporte não motorizado, quando analisados em um contexto mais amplo, seus moradores continuam dependentes das grandes cidades para trabalho e serviços e, consequentemente, aumentam o tráfego nas rodovias regionais.

De qualquer modo, temos que a forma urbana reflete a infraestrutura de transporte e as tecnologias dominantes. Neste sentido, o desenho urbano pode diretamente influenciar na distribuição espacial das funções urbanas, estabelecendo uma densidade desejável para uma ocupação equilibrada. Medidas de planejamento urbano podem ser capazes de conter a dispersão e contribuir efetivamente para a redução das distâncias de deslocamento, incrementando a eficiência do transporte público e fazendo com que o caminhar e o pedalar sejam mais atrativos para as curtas distâncias a percorrer.

Para conter a expansão da cidade do automóvel e recuperar a qualidade de vida urbana, Moller (2006) defende que a cidade deve ser redesenhada à escala do pedestre, ou seja, fomentar a micromobilidade (distâncias curtas a pé ou em bicicleta) e minimizar a macromobilidade (grandes distâncias percorridas em automóveis).

Ewing et al. (2007) salientam cinco diferentes estratégias de desenho urbano que podem influenciar nas distâncias de deslocamento e na eleição de diferentes modais de transporte: os cinco "Ds", do inglês density, diversity, design, destination accessibitity, distance to transit, que, traduzidas ao português, fazem referência às estratégias de densidade, diversidade, características da rede viária, acessibilidade ao destino e distância ao transporte público, respectivamente.
A maioria dos serviços urbanos com relevância à questão ambiental, como o tratamento de águas, transporte e reciclagem de lixo requerem economias de escala e densidade. Em um estudo detalhado sobre a dependência do automóvel na mobilidade de 32 cidades de alta renda da América do Norte, Europa, Austrália e Ásia, posteriormente ampliado para 84 cidades considerando as demais regiões, Newman $(1996,2006)$ constatou que baixos níveis de dependência em automóveis em cidades asiáticas e europeias estavam diretamente associados a elevadas densidades populacionais, sugerindo a ideia de que "quanto mais próximas as pessoas vivem, menores são as distâncias de deslocamento e mais viável torna-se o transporte público" (NEWMAN, 2006, p. 281).

No entanto, Ewing et al. (2007) contrapõem-se aos estudos que generalizam o consumo de energia e emissões de $\mathrm{CO}_{2}$ nos transportes unicamente com base em padrões de densidade populacional; primeiramente porque um adensamento urbano pode significar uma concentração de viagens de um único tipo (para o trabalho, por exemplo, nos centros de negócios) e, consequentemente, incorrer em um aumento dos congestionamentos e à redução da velocidade das viagens, o que resultaria em uma menor economia de energia independente da redução das distâncias de deslocamento.

Além da mistura de funções, uma diversidade estética e formal do ambiente construído, aliada a uma diversidade de grupos culturais e sociais, reforça a presença e o contato humano, satisfazendo os habitantes, aumentando a vitalidade da rua e encorajando o caminhar. Ao contrário, uma paisagem urbana monótona torna-se insegura para o pedestre e acaba por incrementar o uso do automóvel até mesmo para as distâncias mais curtas (JACOBS, 2000; JABAREEN, 2006).

Se o objetivo é construir espaços diversificados que encorajam a convivência e priorizam o transporte não motorizado (TNM), Mascaró (2005) argumenta que não há outra maneira de fazê-lo senão restringindo ao máximo os deslocamentos motorizados e isto apenas será possível com a redução do espaço destinado aos automóveis.

Essa restrição diz respeito não apenas às áreas de estacionamento, que consomem uma grande parcela do solo urbano (entre $10 \mathrm{~m}^{2}$ e $15 \mathrm{~m}^{2}$ por veículo durante mais de 20 horas diárias), mas ao 
ambiente de circulação, que deve reduzir ao máximo os conflitos entre os diferentes modos de transporte e o risco potencial de acidentes graves, principalmente com ciclistas e pedestres (PETERSEN, 2004; VASCONCELLOS, 2006).

Partindo da hipótese de que o desenho urbano tem mais sucesso quanto mais forte forem as conexões entre os nós de atividades humanas, Salingaros (1998) sugere que a conectividade permite às pessoas o alcance de qualquer ponto no espaço urbano por meio de múltiplos caminhos diferentes. Assim, o cruzamento de diferentes redes de diferentes escalas e capacidades operando simultaneamente permite uma conectividade múltipla entre as atividades, determinando a forma da estrutura urbana.

0 desenvolvimento orientado ao transporte público (transit-oriented development - TOD), que prescreve a concentração da população e das atividades em áreas próximas aos serviços de transporte, facilmente percorridas a pé ou em bicicleta e bem servidas por múltiplos itinerários, permite uma concentração das demandas e a maximização da eficiência do transporte coletivo, reduzindo a necessidade de deslocamentos motorizados (CERVERO, 2005; JABAREEN, 2006; LITMAN, 2008d; LUND; CERVERO; WILSON, 2004; NEWMAN, 1996; PETERSEN, 2004).

De acordo com Litman (2008d), estratégias baseadas em TOD tipicamente aumentam de duas a cinco vezes a quantidade de passageiros do transporte público, enquanto reduzem entre $8 \%$ e $32 \%$ o número de viagens em automóveis, comparado ao planejamento do uso do solo convencional.

No entanto, reestruturar a cidade de modo a converter os deslocamentos em automóveis em favor do transporte público, e deste modo contribuir decisivamente para a redução das emissões de GEE, requer também o planejamento da infraestrutura e a garantia de qualidade dos serviços do transporte público (DALKMANN; BRANNIGAN, 2007).

Em outras palavras, a extensão da cobertura geográfica da rede de transportes, a expansão e a melhoria da operação dos serviços ao usuário, a integração modal e a opção por sistemas de transporte rápidos de alta capacidade (mass rapid transit - MRT, ou bus rapid transit - BRT) constituem a chave para tornar o transporte público atrativo, acessível, confiável e eficiente (DALKMANN; BRANNIGAN, 2007).

\section{Medidas tecnológicas}

A Agência Internacional de Energia (IEA, 2006a), em cooperação com o plano de ação do G8 sobre o futuro energético, publicou em 2006 o relatório Energy Technology Perspectives: Scenarios and Strategies to 2050. Esse relatório traz projeções que apontam a prevalência dos combustíveis fósseis como a matriz energética dominante para o ano de 2050 , suprindo em torno de $70 \%$ das necessidades energéticas globais, bem como o aumento de $137 \%$ nas emissões de $\mathrm{CO}_{2}$ em relação aos níveis atuais.

0 principal objetivo desse estudo foi elaborar conjuntos de cenários e estratégias, sob diferentes níveis de desenvolvimento tecnológico, para retroceder as emissões de $\mathrm{CO}_{2}$ abaixo dos níveis atuais até 2050 , contemplando os setores de geração de energia, indústria, transportes e edifícios (IEA, 2006a).

As asserções desse relatório estão fundamentadas em duas diferentes perspectivas com significativa importância ao desenvolvimento tecnológico no setor de transportes: Accelerated Technology Scenarios (ACT, na sigla em inglês) e TECH Plus Scenario (IEA, 2006a). 0 primeiro cenário, mais realista, ilustra o grande potencial que as tecnologias existentes ou que estão em desenvolvimento e entrarão no mercado nos próximos 20 anos possuem para a redução do consumo global de combustíveis fósseis e para a redução das emissões de $\mathrm{CO}_{2}$ abaixo dos níveis atuais em 2050. Essas tecnologias focam principalmente a melhoria da eficiência energética nos setores de transporte, indústria e edifícios, além da substituição de fontes energéticas na geração de energia, e o amplo uso de biocombustíveis nos transportes (IEA, 2006a).

Apesar do reconhecimento de que os deslocamentos motorizados irão aumentar quase $150 \%$ até 2050, o melhoramento da eficiência energética, segundo o cenário ACT, contribuiria para uma redução de $50 \%$ no consumo energético dos automóveis neste período. Dessa forma, auxiliaria na redução de aproximadamente $17 \%$ das emissões de $\mathrm{CO}_{2}$ em relação ao estimado para o ano de 2050 no setor de transportes (IEA, 2006a).

Uma visão mais otimista, e ambiciosa, é a definida pelo segundo cenário, TECH Plus Scenario, que resultaria nas emissões de $\mathrm{CO}_{2}$ sendo reduzidas em $16 \%$ abaixo dos níveis atuais até 2050 , mediante o 
amplo uso de energia renovável e nuclear na geração de energia, e uma maior participação dos biocombustíveis e do hidrogênio na demanda final de energia no setor de transportes (IEA, 2006a).

Segundo esse enfoque, os transportes contribuiriam com $26 \%$ de redução das emissões de $\mathrm{CO}_{2}$ até 2050 considerando todos os setores da economia, sobretudo em virtude do incremento da participação de veículos movidos a células de hidrogênio na frota total de veículos (IEA, 2006a).

Em ambos os casos, os melhoramentos nas tecnologias veiculares existentes - o que inclui a redução do carregamento e peso do veículo, alterações no design e aerodinâmica e componentes internos como os sistemas de calefação e refrigeração - são as estratégias mais promissoras para incrementar a eficiência energética em curto prazo e auxiliar na redução das emissões de GEE (IEA, 2006a; RIBEIRO et al., 2007).

O Gráfico 1 ilustra a contribuição de diferentes medidas tecnológicas no aumento da eficiência energética em automóveis segundo o cenário ACT, ressaltando os motores híbridos e melhorias nos sistemas internos de combustão nos maiores ganhos (IEA, 2006a).

Alguns desses melhoramentos tecnológicos são polêmicos, pois, segundo alguns estudos, eles indicam uma melhor eficiência quando o veículo já está

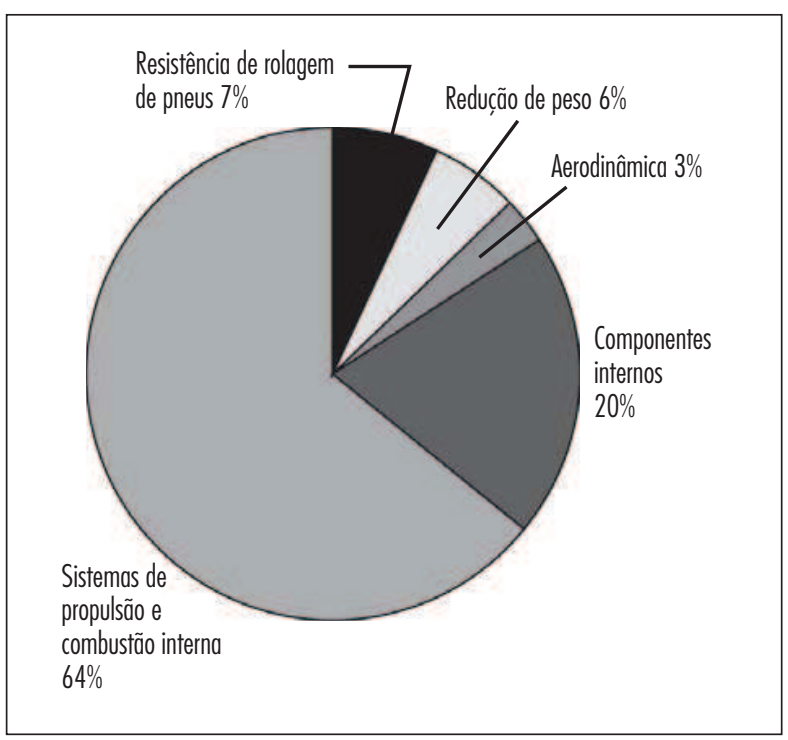

Gráfico 1 - Contribuição de diferentes medidas tecnológicas no aumento da eficiência em automóveis

Fonte: Adaptado de IEA (2006a). em funcionamento, não contabilizando o consumo energético e o consequente impacto ambiental durante sua produção. É o caso da mudança do aço para o alumínio. A diminuição do peso do veículo poderia lhe trazer melhor desempenho energético. Porém, conforme aponta a WBCSD (2004), se somente o alumínio fosse utilizado para a redução do peso de um veículo, até $45 \%$ da economia de energia que seria alcançada no ciclo de vida útil deste veículo seria perdida no processo de obtenção do material. Há alternativas, como afirmam Ribeiro et al. (2007), que apontam para o fato de que a substituição do aço convencional por ligas de aço de alta resistência pode reduzir o peso de um veículo entre 19\% e $32 \%$.

Contudo, uma grande quantidade de energia consumida pelos veículos e que usualmente não é contabilizada provém de sistemas internos, utilizados para incrementar o conforto dos usuários, como os sistemas de controle de temperatura (WBCSD, 2004). Sistemas de ar-condicionado podem contar por aproximadamente $50 \%$ do consumo energético de um veículo (IEA, 2006a) e, como Ribeiro et al. (2007) ressaltam, contribuindo nas emissões de GEE tanto diretamente, pelo uso de gás refrigerante, como indiretamente, pelo consumo de combustíveis fósseis.

Melhorias tecnológicas nestes sistemas incluem a utilização de gases refrigerantes com baixas emissões, um maior controle do fluxo de ar interno, a instalação de painéis solares nos veículos de modo a reduzir a demanda de energia elétrica pelos componentes internos e a utilização de películas refletivas nos vidros dos veículos (IEA, 2005, 2006a; WBCSD, 2004).

Tecnologias eletrônicas avançadas de combustão interna, como a injeção direta, o controle de válvulas e sistemas de transmissão automática, podem auxiliar na redução de $30 \%$ do tamanho dos motores, o significa uma redução no consumo de combustível e nas emissões de $\mathrm{CO}_{2}$ e outros poluentes locais (WBCSD, 2004).

A IEA (2006a, p. 253) afirma que "se estas tecnologias veiculares forem implementadas, $40 \%$ de economia em combustíveis nos veículos a gasolina podem ser alcançados a baixo custo até 2050".

Os veículos híbridos têm seu desenvolvimento tecnológico e produção comercial crescente e presente nas principais feiras automobilísticas 
internacionais. $\mathrm{O}$ alto custo da tecnologia ainda é a principal barreira para a sua expansão no mercado. Mas no longo prazo, veículos elétricos, por exemplo, além de poderem consumir energia menos impactante, ainda poderiam gerar energia para a rede - como exploram Mitchell, Borroni-Bird e Burns (2010). Os veículos urbanos seriam, então, reduzidos em tamanho, em impacto ambiental, e ainda participariam de uma rede de transporte público e de distribuição de energia.

Os veículos totalmente elétricos podem apresentar mais de 90\% de eficiência energética, além de significar uma redução de mais de $50 \%$ nas emissões de $\mathrm{CO}_{2}$ em uma análise well-to-wheels ("do poço às rodas"), que considera o ciclo total da energia desde sua produção até a utilização no veículo, comparados aos veículos convencionais de combustão interna à gasolina (RIBEIRO et al., 2007).

A utilização de gás natural como combustível para veículos também é uma solução que vem sendo adotada amplamente. Em Nova Déli, toda a frota do transporte público circula com gás natural. Entretanto, embora o gás natural produza menores quantidades de $\mathrm{CO}_{2}$, o principal gás emitido é o metano $\left(\mathrm{CH}_{4}\right)$ que, apesar de ser considerado um gás menos danoso à saúde humana que os gases de escape provenientes dos motores convencionais (LOBKOV et al., 2006), é o gás que apresenta maior participação no efeito estufa depois do $\mathrm{CO}_{2}$ (INTERGOVERNMENTAL PANEL ON CLIMATE CHANGE - IPCC, 2007).

No Brasil, a grande disponibilidade de etanol a um custo de produção reduzido e a expansão do mercado de veículos flex, que permitem o uso tanto da gasolina como do etanol com uma mínima alteração do sistema interno, aliadas à instabilidade dos preços do petróleo, reacenderam a política do álcool no país, produto que, na década de 1980, chegou a responder por $90 \%$ dos combustíveis utilizados nos transportes (IEA, 2006b).

Segundo Vasconcellos (2006), o atual estágio de utilização do etanol no Brasil é responsável pela redução das emissões de $\mathrm{Pb}$ e $\mathrm{CO}$ da gasolina e pela redução de $10 \%$ nas emissões totais de $\mathrm{CO}_{2}$ nos transportes.

Apesar de existir pouca discordância de que os veículos movidos a $\mathrm{H}_{2}$ venham a se desenvolver no futuro, as questões que vêm à tona na literatura científica dizem respeito principalmente a como o hidrogênio será obtido, no que concerne ao custo, consumo de energia e emissões de GEE. De acordo com Walsh e Kolke (2005), o $\mathrm{H}_{2}$ é o elemento químico em maior abundância no planeta, mas não é uma energia primária, requerendo, portanto, o consumo de uma determinada quantidade de energia, renovável ou não renovável, para obtê-lo a partir de fontes fósseis ou não fósseis. Como Lobkov et al. (2006, p. 118) acrescentam, "se o hidrogênio for gerado através da eletrólise da água o nível de poluição é zero, se o hidrogênio for gerado da reforma de hidrocarbonetos ou da gaseificação da biomassa haverá emissão de $\mathrm{CO}_{2}{ }^{\prime \prime}$.

Reduzir as emissões de $\mathrm{CO}_{2}$ abaixo dos níveis atuais até 2050 pode criar uma oportunidade para a estabilização da concentração atmosférica deste gás. Para tanto, será necessário que essas diferentes estratégias tecnológicas continuem na segunda metade do século XXI, especialmente para o setor de transportes, mas contando com o auxílio e concordância do setor público e privado, a intervenção de políticas adicionais e a cooperação mútua entre os países desenvolvidos e os países em desenvolvimento.

Os Quadros 4, 5 e 6 evidenciam estudos de caso destacados pela literatura científica de aplicação de algumas das principais tecnologias discutidas nesta seção.

\section{Considerações finais}

O setor de transportes é um dos principais emissores de gases poluentes. E a mobilidade urbana conhece nos últimos anos uma crescente motorização individual. Além de agravar o problema ambiental, com o excesso de emissão de gases de efeito estufa, a motorização privada consome espaço urbano tanto com vias para circulação de automóveis como com extensas áreas para estacionamento, que degradam a qualidade de vida urbana.

Neste artigo, nosso enfoque foi sobre os impactos ambientais da mobilidade urbana. Em especial, procuramos analisar algumas soluções que vêm sendo discutidas para a redução das emissões de GEE, mais especificamente o $\mathrm{CO}_{2}$, na mobilidade urbana. Apesar de serem várias as medidas propostas - várias delas inclusive adotadas em alguns países - foi possível reuni-las em cinco grupos de medidas mitigadoras 
Quadro 4 - Estudos de caso de aplicação de medidas tecnológicas: Ford P2000 e Toyota Prius

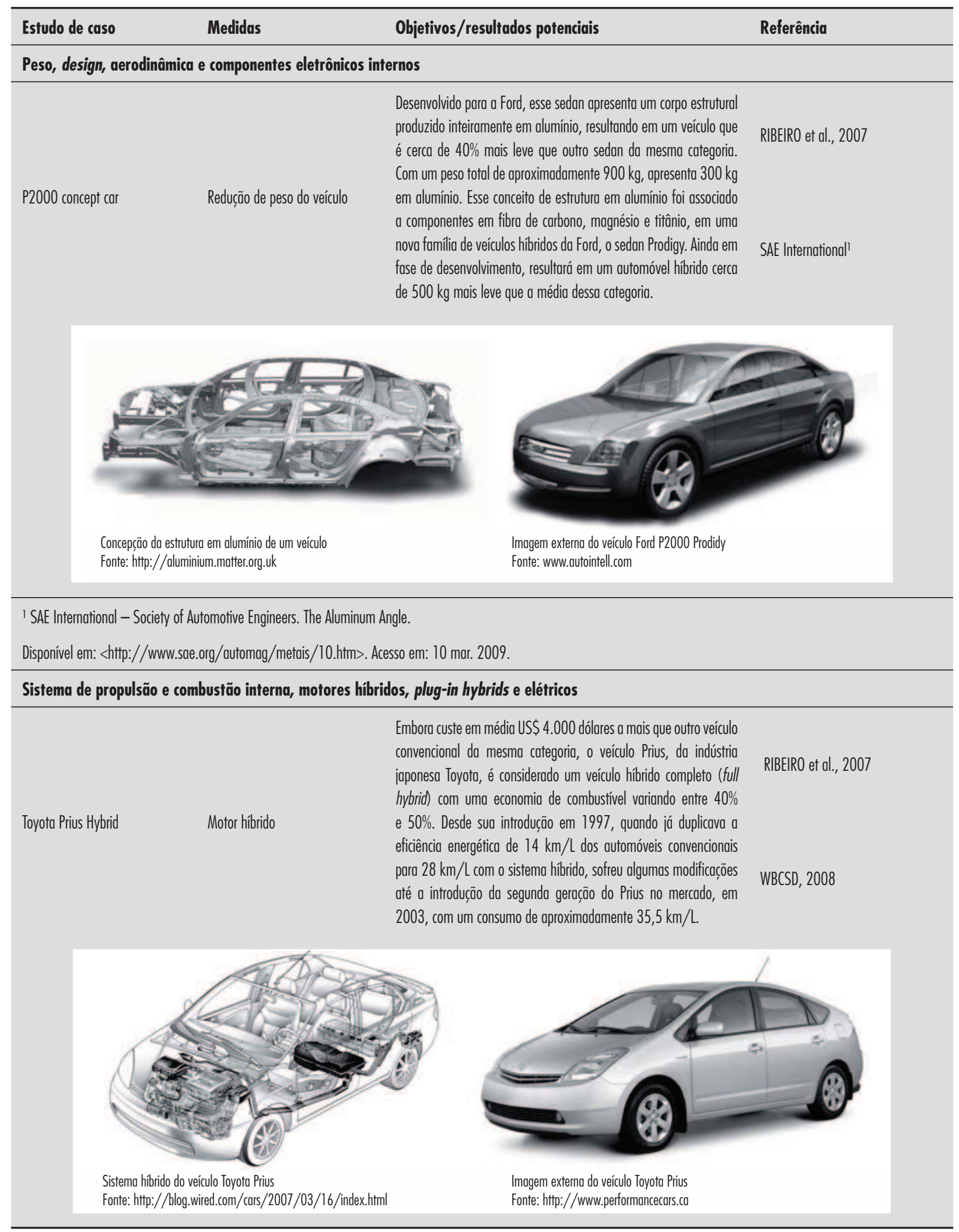

Fonte: BARCZAK, 2009.

urbe. Revista Brasileira de Gestão Urbana (Brazilian Journal of Urban Management), v. 4, n. 1, p. 13-32, jan./jun. 2012 
Quadro 5 - Estudos de caso de aplicação de medidas tecnológicas: Ônibus Phileas e GM Volt

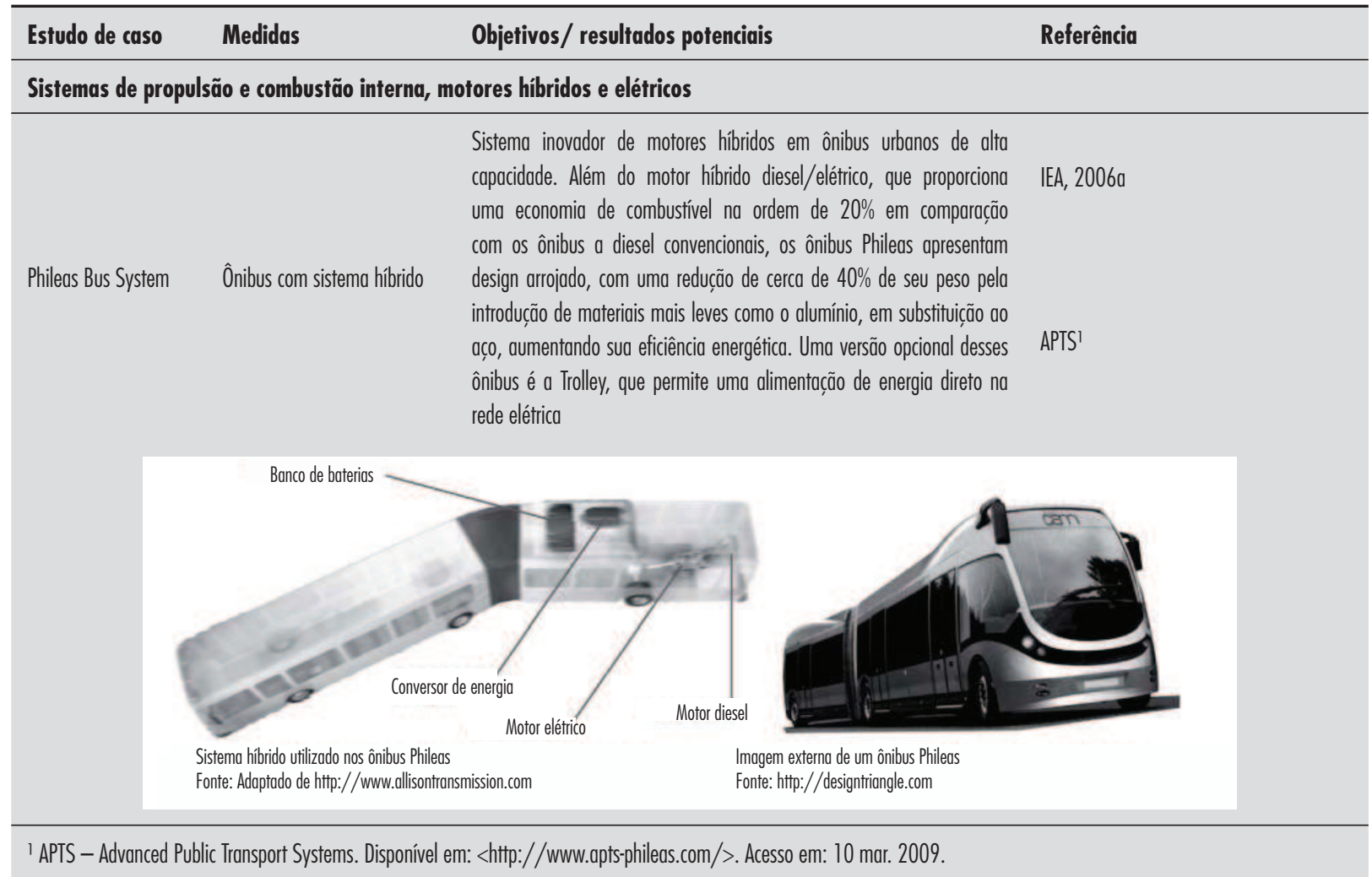

Considerado pela General Motors mais como um veículo elétrico (EV) do que um veículo híbrido, o Chevrolet Volt apresenta um sistema de propulsão baseado unicamente em um motor elétrico de 45 KW (1). 0 veículo apresenta uma autonomia de $65 \mathrm{~km}$ utilizando apenas a energia elétrica armazenada nas baterias de Lítio-lon (2), que podem ser

GM Volt Plug-in Hybrid Eletric Vehicle (PHEV) recarregadas diretamente na rede elétrica comum, em voltagens de $110 \mathrm{v}$ ou 220v, com plug comum (3). 0 diferencial desse veículo é que ele apresenta um pequeno motor de combustão interna do tipo flexfuel (4), que aceita tanto a gasolina como 0 etanol (E85), mas cuja única função é trabalhar como um gerador adicional de eletricidade, que aumenta a autonomia do veículo para $650 \mathrm{~km}$. Sua entrada no mercado de veículos novos está programada para 2010.

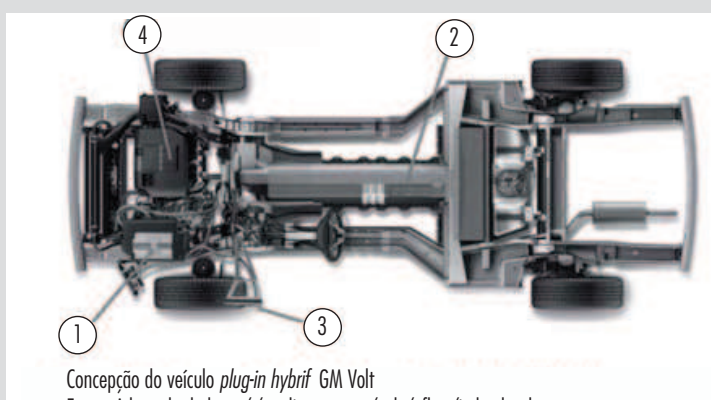

Fonte: Adaptado de http://media.gm.com/volt/eflex/index.html

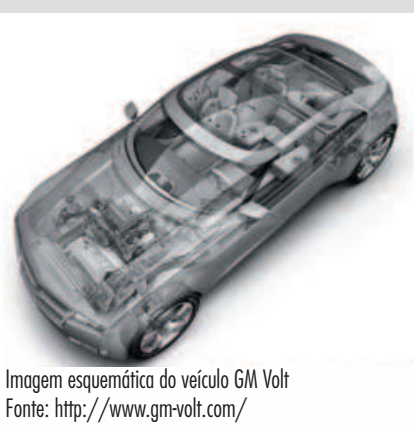

Fonte: hitp://www.gm-volt.com/

${ }^{2}$ GM-VOLT: Chevy Volt Electric Car Site. Disponível em: <http://gm-volt.com/>. Acesso em: 13 mar. 2009.

Fonte: BARCZAK, 2009. 
Quadro 6 - Estudos de caso de aplicação de medidas tecnológicas: Fiat Múltipla e ônibus híbrido e a hidrogênio

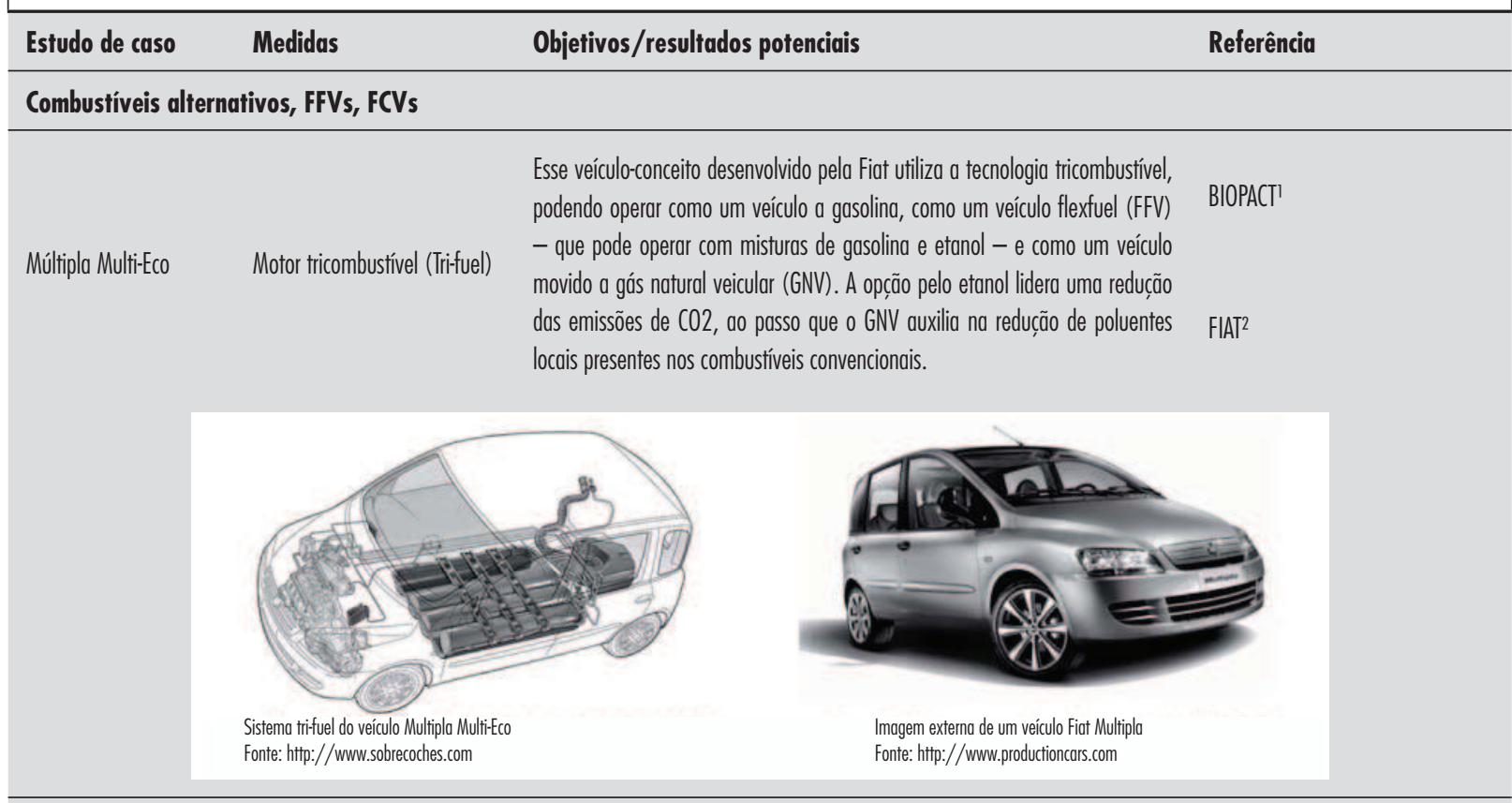

' BIOPACT. Disponível em: <http://news.mongabay.com/bioenergy/2006_09_20_archive.html>. Acesso em: 13 mar. 2009.

2 FIAT. Disponível em: <http://www.fiat.com>. Acesso em 14 mar. 2009.

\begin{tabular}{|c|c|c|c|}
\hline \multirow[t]{2}{*}{ Ônibus brasileiro $\mathrm{H}_{2}$} & CaC Hidrogênio & 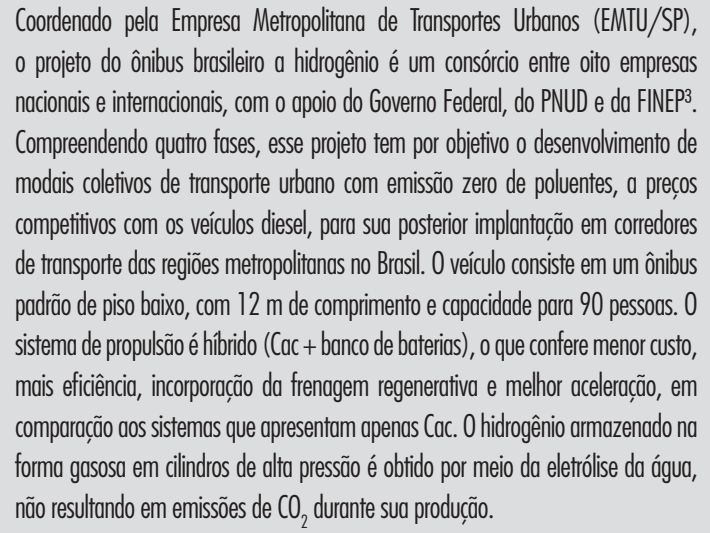 & $\begin{array}{l}\text { SCHETTINO; RIBEIRO, } 2005 \\
\text { NETO et al., } 2007\end{array}$ \\
\hline & $\begin{array}{l}\text { Sistema hibrido (Cac/e } \\
\text { Fonte: Adaptado de hitr }\end{array}$ & $\begin{array}{l}\text { Montrole de potência } \\
\text { Porta de abastecimento } \\
\text { pela Toyota } \\
\mathrm{m} / \mathrm{mt} / \text { orchives/pic/etc/toyota.jpg }\end{array}$ & \\
\hline
\end{tabular}

Fonte: BARCZAK, 2009.

urbe. Revista Brasileira de Gestão Urbana (Brazilian Journal of Urban Management), v. 4, n. 1, p. 13-32, jan./jun. 2012 
dos impactos ambientais decorrentes da mobilidade urbana. Esses cinco grupos são de medidas econômico-fiscais e financeiras; regulatórias; de informação e comunicação; de planejamento urbano; e tecnológicas.

Não é segredo que nenhuma delas poderia sozinha resolver o problema. Para cada uma foram apontados seus pontos positivos, mas também seus eventuais reveses. Foi inevitável chegarmos à conclusão de que apenas a articulação de medidas de cada um dos grupos poderia, de fato, ser eficaz na redução dos impactos ambientais da mobilidade urbana.

Porém, o que se constata é que durante certo tempo, principalmente nos anos 1990, as medidas regulatórias e econômico-fiscais e financeiras, que restringem o uso de automóveis em determinadas áreas ou penaliza financeiramente sua circulação (por exemplo), eram as mais comuns. Nos últimos anos, as medidas de informação e comunicação têm ganhado importância, exatamente quando as vendas de veículos cresceram - como uma tentativa de alertar a população de que esse indicador de saúde financeira (poder possuir um veículo) significa também a perda da qualidade de vida urbana. Finalmente, é bem mais recente a rapidez nos melhoramentos tecnológicos. Certamente, em função da crescente preocupação dos países ricos com os efeitos perversos para o meio ambiente da motorização e a combinada expansão do mercado de carros nos países emergentes e populosos (como China, Brasil e Índica, por exemplo), a indústria automobilística despertou para o problema: de um lado, deverá enfrentar pressões dos países onde estão suas matrizes; de outro, não pode perder o mercado gigantesco dos países em desenvolvimento.

O problema neste sentido é que as medidas tecnológicas visam somente ao melhoramento do desempenho dos veículos - mas, justamente, mantendo os veículos circulando. Quanto mais veículos, melhor; fato que inviabiliza qualquer programa de redução de impactos ambientais decorrentes da mobilidade urbana.

Assim, cabe retomar a óbvia conclusão de que apenas a combinação entre esses conjuntos de medidas, com destaque para as de planejamento urbano, pois alteram a distribuição e articulação das atividades na cidade, é que será capaz de favorecer uma mobilidade urbana de qualidade que tenha menos impactos negativos no meio ambiente.

\section{Referências}

ACSELRAD, H. A duração das cidades: sustentabilidade e risco nas políticas urbanas. Rio de Janeiro: DP\&A, 2001.

ANDRADE, C. Detran descarta rodízio por causa da "cultura do carro" que Brasília tem desde as origens. UOL Notícias, 27 maio 2008. Disponível em: <http://noticias.uol.com.br/especiais/transito/2008/05/27/ult5848u27.jhtm>. Acesso em: 16 jan. 2011.

ASSOCIAÇÃO NACIONAL DE TRANSPORTES PÚBLICOS ANTP. Mobilidade e cidadania. São Paulo: ANTP, 2003.

ASSOCIAÇÃO NACIONAL DE TRANSPORTES PÚBLICOS ANTP. Relatório geral de mobilidade urbana 2007. Sistema de informações da mobilidade urbana. São Paulo: ANTP, 2008. Disponível em: <www.antp.org.br>. Acesso em: 16 jan. 2011.

BARCZAK, R. Estratégias de mitigação e compensação das emissões de CO2 na mobilidade urbana: uma análise da produção científica internacional. 2009. 289 f. Dissertação (Mestrado em Gestão Urbana) - Pontifícia Universidade Católica do Paraná, Curitiba, 2009.

BRASIL. Ministério das Cidades. Gestão integrada da mobilidade urbana: curso de capacitação. Brasília: Ministério das Cidades, 2006.

BREITHAUPT, M. Economic and fiscal policy instruments. In: INTERNATIONAL CONFERENCE ON SUSTAINABLE TRANSPORTATION \& CLEAN AIR, 2000. Proceedings... Jakarta, Germany: Deutsche Gesellschaft für Technische Zusammenarbeit GTZ, 2000. Disponível em: <www.gtz. de>. Acesso em: 16 jan. 2011.

BREITHAUPT, M. Economic instruments: sustainable transport - sourcebook for policy-makers in developing cities. Module 1d. Eschborn: Deutsche Gesellschaft für Technische Zusammenarbeit GTZ, 2006. Disponível em: <www.sutp.org>. Acesso em: 16 jan. 2011.

BREITHAUPT, M.; EBERZ, O. Ecodriving: sustainable transport - sourcebook for policy-makers in developing cities. Module 4f. Eschborn: Deutsche Gesellschaft für Technische Zusammenarbeit GTZ, 2005. Disponível em: <www.sutp.org>. Acesso em: 16 jan. 2011.

CERVERO, R. Transit oriented development in America: strategies, issues, policy directions. Fremantle: Western Australian Planning Commission, 2005. 
DALKMANN, H.; BRANNIGAN, C. Transport and climate change: sustainable transport: sourcebook for policy-makers in developing cities. Module 5e. Eschborn: Deutsche Gesellschaft für Technische Zusammenarbeit GTZ, 2007. Disponível em: <www.sutp.org>. Acesso em: 16 jan. 2011.

DAY, K. New urbanism and the challenges of designing for diversity. Journal of Planning Education and Research, v. 23, n. 1, p. 83-95, 2003. Disponível em: <http://jpe. sagepub.com/cgi/content/abstract/23/1/83>. Acesso em: 16 jan. 2011.

EWING, R. et al. Growing cooler: the evidence on urban development and climate change. Chicago: Urban Land Institute, 2007.

FISCHER, G. et al. Climate change impacts on irrigation water requirements: effects of mitigation, 1990-2080. Technological Forecasting \& Social Change, v. 74, p. 1083-1107, 2007.

GOEDEKING, U. Air polluters on the retreat. Akzente Special, Eschborn, p. 6-9, abr. 2004. Disponível em: <www.gtz.de>. Acesso em: 16 jan. 2011.

GRÜTTER, J. The CDM in the transport sector: sustainable transport sourcebook for policy-makers in developing cities. Modul e 5d. Eschborn: Deutsche Gesellschaft für Technische Zusammenarbeit GTZ, 2007. Disponível em: <www.sutp.org>. Acesso em: 16 jan. 2011.

HALSNAES, K. et al. Climate change 2007: framing issues. In: INTERGOVERNMENTAL PANEL ON CLIMATE CHANGE - IPCC. Climate change 2007: mitigation. Contribution of Working Group III to the Fourth Assessment Report of the Intergovernmental Panel on Climate Change. New York: Cambridge University Press, 2007.

INTERNACIONAL ENERGY AGENCY - IEA. Making cars more fuel efficient: technology for real improvements on the road. Paris: IEA; OECD, 2005. Disponível em: <http://www.iea.org>. Acesso em: 4 mar. 2009.

INTERNACIONAL ENERGY AGENCY - IEA. Energy technology perspectives 2006: scenarios \& strategies to 2050. Paris: IEA; OECD, 2006a. Disponível em: <http:// www.iea.org/Textbase/npsum/enertech2006SUM.pdf>. Acesso em: 16 jan. 2011.

INTERNACIONAL ENERGY AGENCY - IEA. World energy outlook 2006. Paris: IEA; OECD, 2006b. Disponível em: <http://www.iea.org>. Acesso em: 23 ago. 2008.
INTERGOVERNMENTAL PANEL ON CLIMATE CHANGE - IPCC. Summary for policymakers. In: INTERGOVERNMENTAL PANEL ON CLIMATE CHANGE IPCC. Climate Change 2007: the physical science basis. Contribution of Working Group I to the Fourth Assessment Report of the Intergovernmental Panel on Climate Change. New York: Cambridge University Press, 2007.

JABAREEN, Y. R. Sustainable urban forms: their typologies, models, and concepts. Journal of Planning Education and Research, v. 26, n. 1, p. 38-52, 2006. Disponível em: <http://jpe.sagepub.com/cgi/content/ abstract/26/1/38>. Acesso em: 8 abr. 2008.

JACOBS, J. Morte e vida de grandes cidades. São Paulo: M. Fontes, 2000.

KENWORTHY, J. R. The eco-city: ten key transport and planning dimensions for sustainable city development. Environment and Urbanization, v. 18, n. 1, p. 67-85, abr. 2006. Disponível em: <http://eau.sagepub.com/cgi/content/abstract/18/1/67>. Acesso em: 8 abr. 2008.

KOLKE, R. Inspection \& maintenance and roadworthiness: sustainable transport: sourcebook for policy-makers in developing cities. Module 4b. Eschborn: Deutsche Gesellschaft für Technische Zusammenarbeit GTZ, 2006. Disponível em: <www.sutp.org>. Acesso em: 16 jan. 2011.

LANFREDI, G. F. Política ambiental: busca de efetividade de seus instrumentos. 2. ed. São Paulo: Revista dos Tribunais, 2007.

LEFF, E. Saber ambiental: sustentabilidade, racionalidade, complexidade, poder. Petrópolis: Vozes, 2001.

LITMAN, T. Win-Win emission reduction strategies: smart transportation strategies can achieve emission reduction targets and provide other important economic, social and environmental benefits. Canadá: Victoria Transport Policy Institute VTPI, 2008a. Disponível em: <http://www.vtpi.org> Acesso em: 16 jan. 2011.

LITMAN, T. Win-Win transportation solutions: mobility management strategies that provide economic, social and environmental benefits. Canadá: Victoria Transport Policy Institute VTPI, 2008b. Disponível em: <http:// www.vtpi.org>. Acesso em: 16 jan. 2011.

LITMAN, T. Smart transportation emissions reductions: identifying truly optimal energy conservation and emission reduction strategies. Canadá: Victoria Transport Policy Institute VTPI, 2008c. Disponível em: <http://www.vtpi.org>. Acesso em: 4 ago. 2008. 
LITMAN, T. Land use impacts on transport. Canadá: Victoria Transport Policy Institute VTPI, 2008d. Disponível em: <http://www.vtpi.org>. Acesso em: 24 mar. 2009.

LOBKOV, D. D. et al. Uso de combustíveis gasosos em transporte urbano. Revista dos Transportes Públicos, v. 112, p. 111-122, 2006.

LUND, H. M.; CERVERO, R.; WILLSON, R. W. Travel characteristics of transit-focused development in California. Oakland: Bay Area Rapid Transit District and California Department of Transportation, 2004.

LUSTOSA, M. C. J.; CANEPA, E. M.; YOUNG, C. E. F. Política ambiental. In: MAY, P. H.; LUSTOSA, M. C.; VINHA, V. (Org.). Economia do meio ambiente: teoria e prática. Rio de Janeiro: Elsevier, 2003.

MASCARO, J. L. Loteamentos urbanos. Porto Alegre: Edição do Autor, 2005.

MITCHELL, W. J.; BORRONI-BIRD, C. E.; BURNS, L. D. Reinventing the automobile. Cambridge, MA: MIT Press, 2010.

MOLLER, R. Transporte urbano y desarrollo sostenible en América Latina: el ejemplo de Santiago de Cali, Colombia. Cali: Programa Editorial Universidad del Valle, 2006.

MONTEZUMA, R. Bogotá's transformation: citizen and spatial redefinition. Bogotá, Colombia: Fundación Ciudad Humana, 2003.

NETO, A. J. M. et al. A utilização do hidrogênio como combustível para ônibus elétricos. Revista dos Transportes Públicos, n. 116, p. 61-75, 2007.

NEWMAN, P. Reducing automobile dependence. Environment and Urbanization, v. 8, n. 1, p. 67-92, abr. 1996. Disponível em: <http://eau.sagepub.com/cgi/content/abstract/8/1/67>. Acesso em: 8 abr. 2008.

NEWMAN, P. The environmental impact of cities. Environment and Urbanization, v. 18, n. 2, p. 275-295, Oct. 2006. Disponível em: <http://eau.sagepub.com/cgi/ content/abstract/18/2/275>. Acesso em: 6 maio 2008.

PARDO, C. F. Raising public awareness about sustainable urban transport: sustainable transport: sourcebook for policy-makers in developing cities. Module 1e. Eschborn: Deutsche Gesellschaft für Technische Zusammenarbeit GTZ, 2006. Disponível em: <www.sutp. org>. Acesso em: 16 jan. 2011.
PETERSEN, R. Land use planning and urban transport: sustainable transport: sourcebook for policy-makers in developing cities. Module 2a. Eschborn: Deutsche Gesellschaft für Technische Zusammenarbeit GTZ, 2004. Disponível em: <www.sutp.org>. Acesso em: 16 jan. 2011.

RIBEIRO, S. K. et al. Climate change 2007: transport and its infrastructure. In: INTERGOVERNMENTAL PANEL ON CLIMATE CHANGE - IPCC. Climate change 2007: mitigation. Contribution of Working Group III to the Fourth Assessment Report of the Intergovernmental Panel on Climate Change. New York: Cambridge University Press, 2007.

SALINGAROS, N. A. A teoria da teia urbana. Trad. de Lívia Salomão Piccinini. Journal of Urban Design, v. 3, p. 53-71, 1998. Disponível em: <http://zeta.math.utsa. edu/ yxk833/>. Acesso em: 15 out. 2008.

SAYEG, P.; CHARLES, P. Intelligent transport systems: sustainable transport: sourcebook for policy-makers in developing cities. Module 4e. Eschborn: Deutsche Gesellschaft für Technische Zusammenarbeit GTZ, 2005. Disponível em: <www.sutp.org>. Acesso em: 16 jan. 2011.

SCARINGELLA, R. A crise da mobilidade urbana em São Paulo. São Paulo em Perspectiva, v. 15, n. 1, p. 55-59, jan./mar. 2001.

SCHETTINO, M. R. A.; RIBEIRO, O. O. Estratégia energético-ambiental: ônibus com célula a combustível hidrogênio para o Brasil. In: CONGRESSO BRASILEIRO DE TRANSPORTE E TRÂNSITO, 15., 2005, Goiânia. Anais... Goiânia: ANTP, 2005. Disponível em: <http://www.emtu.sp.gov.br/artigos/ menu.htm?arq=3> Acesso em: 14 mar. 2009.

SCHMITT, R. S. Impactos da implantação de medidas de gerenciamento da mobilidade em uma área urbana com múltiplos pólos atratores de viagens. 2006. 194 f. Dissertação (Mestrado em Engenharia da informação) - Universidade Federal do Rio Grande do Sul, Porto Alegre, 2006.

SCHWAAB, J. A.; THIELMANN, S. Economic instruments for sustainable road transport: an overview for policy makers in developing countries. Eschborn: Deutsche Gesellschaft für Technische Zusammenarbeit GTZ, 2001. Disponível em:<www.sutp.org>. Acesso em: 16 jan. 2011.

VASCONCELLOS, E. A. Quantificação das deseconomias do transporte urbano: uma resenha das experiências internacionais. Textos para discussão IPEA, Brasília, n. 586, 1998. Disponível em: <http://www.ipea.gov.br/ agencia/index.php?option=com_content\&view=article\&i $\mathrm{d}=3862$ \&Itemid=2>. Acesso em: 16 jan. 2011. 
VASCONCELLOS, E. A. Transporte e meio ambiente: conceitos e informações para análise de impactos. São Paulo: Edição do Autor, 2006.

VICTORIA TRANSPORT POLICY INSTITUTE - VTPI. Online TDM encyclopedia. Canadá: VTPI, 2009. Disponível em: <http://www.vtpi.org>. Acesso em: 16 jan. 2011.

WALKER, G.; KING, D. 0 tema quente: como combater o aquecimento global e manter as luzes acesas. Rio de Janeiro: Objetiva, 2008.

WALSH, M.; KOLKE, R. Cleaner fuels and vehicle technologies: sustainable transport: sourcebook for policy-makers in developing cities. Module 4a. Eschborn: Deutsche Gesellschaft für Technische Zusammenarbeit GTZ, 2005. Disponível em: <www.sutp.org>. Acesso em: 16 jan. 2011.

WORLD BUSINESS COUNCIL FOR SUSTAINABLE DEVELOPMENT - WBCSD. Mobility 2001: world mobility at the end of the twentieth century. Geneva: WBCSD, 2002. Disponível em: <www.wbcsd.org>. Acesso em: 16 jan. 2011.

WORLD BUSINESS COUNCIL FOR SUSTAINABLE DEVELOPMENT - WBCSD. Mobility 2030: meeting the challenges to sustainability. The sustainable mobility project full report 2004. Geneva: WBCSD, 2004. Disponível em: <www.wbcsd.org>. Acesso em: 11 jul. 2008.
WORLD BUSINESS COUNCIL FOR SUSTAINABLE DEVELOPMENT - WBCSD. Mobility for development: facts and trends. Geneva: WBCSD, 2008. Disponível em: <www.wbcsd.org>. Acesso em: 11 jul. 2008.

WRIGHT, L. Bus rapid transit: sustainable transport: sourcebook for policy-makers in developing cities. Module 3b. Eschborn: Deutsche Gesellschaft für Technische Zusammenarbeit GTZ, 2005. Disponível em <www.sutp.org>. Acesso em: 16 jan. 2011.

WRIGHT, L. Car-free development: sustainable transport - sourcebook for policy-makers in developing cities. Module 3e. Eschborn: Deutsche Gesellschaft für Technische Zusammenarbeit GTZ, 2006. Disponível em: <www.sutp.org>. Acesso em: 16 jan. 2011.

WRIGHT, L.; FULTON, L. Climate change mitigation and transport in developing nations. Transport Reviews, v. 25, n. 6, p. 691-717, Nov. 2005. Disponível em: <http:// www.cleanairnet.org/caiasia/1412/articles-70119_paper.pdf>. Acesso em: 17 jul. 2008.

Recebido: $17 / 01 / 2011$

Received: 01/17/ 2011

Aprovado: 05/07/2011

Approved: 07/05/2011 